\title{
ANALISIS POSTUR KERJA PADA BAGIAN GUDANG MUAT GREY DIPT SURYA PUTRA MULIA
}

\author{
Ambang Rizki Aji Nugrahanto', Maria Puspita Sari* \\ ${ }^{1}$ Program Studi Teknik Industri/ Universitas Veteran Bangun Nusantara / \\ ambangnugrahanto@gmail.com \\ ${ }^{2}$ Program Studi Teknik Industri / Universitas Veteran Bangun Nusantara / \\ puspitamaria20@gmail.com
}

\begin{abstract}
PT Surya Putra Mulia is a company that produces gray (greige) using the knitting process. This research is focused on the warehouse section on the loading process finished goods. In the warehouse section there are some excessive physical activities due to activities are carried out manually. Measurement of work posture is needed to determine whether the work posture carried out by the operator is good and ergonomic. Assessment of work posture is carried out using the Rapid Entire Body Assessment (REBA) method. Based on an assessment using the REBA (Rapid Entire Body Assessment) method, it shows that the withdrawal of finished goods includes a moderate level of risk, which means that improvements are needed. The activity of loading finished goods onto trucks (figure 3) includes a moderate risk level which means that repairs are needed, while in Figure 4 it is a high risk level which means that immediate corrective action is needed. For the preparation of finished goods on trucks, it is a moderate risk level, which means that repairs are needed. So that in the process of withdrawing finished goods, proposals are given to reduce the burden being transported. Then add a tool in the process of loading finished goods to the truck in the form of a hand stacker.
\end{abstract}

Keywords : work posture, REBA

\section{ABSTRAK}

PT Surya Putra Mulia adalah perusahaan yang memproduksi grey (greige) dengan menggunakan proses rajut (knitting). Penelitian ini difokuskan dibagian gudang pada proses muat barang jadi. Pada bagian gudang terdapat beberapa aktivitas fisik yang berlebih dikarenakan pada aktivitasnya dilakukan secara manual handling. Pengukuran postur kerja diperlukan untuk mengetahui apakah postur kerja yang dilakukan oleh operator sudah baik dan ergonomis. Penilaian postur kerja dilakukan dengan menggunakan metode Rapid Entire Body Assessment (REBA). Berdasarkan penilaian dengan metode REBA (Rapid Entire Body Assesment) menunjukkan bahwa kegiatan penarikan barang jadi termasuk level risiko sedang yang berarti diperlukan perbaikan. Untuk kegiatan muat barang jadi ke truk termasuk level risiko sedang yang berarti diperlukan perbaikan, sedangkan pada operator 2 muat barang jadi ke truk level risiko tinggi yang berarti diperlukan tindakan perbaikan segera. Untuk kegiatan penyusunan barang jadi di truk termasuk level risiko sedang yang berarti diperlukan perbaikan. Sehingga pada proses penarikan barang jadi diberikan usulan dengan mengurangi beban yang diangkut. Kemudian menambahkan alat bantu pada proses muat barang jadi ke truk berupa hand stacker.

Kata Kunci : postur kerja, REBA, grey

\section{PENDAHULUAN}

PT Surya Putra Mulia adalah perusahaan yang bergerak dibidang pembuatan grey. Pada aktivitasnya terbagi menjadi beberapa bagian yakni penerimaan bahan baku, proses produksi, penimbangan barang jadi, quality control, penyimpanan barang jadi serta pemasaran. Pada divisi gudang terdapat beberapa aktivitas yang dilakukan oleh operator di gudang dimulai dengan bongkar bahan baku, penyusunan bahan baku yang disusun diatas pallet, pemindahan bahan baku ke line produksi, penyusunan barang jadi yang disusun diatas pallet, pemindahan barang jadi yang telah disusun ke lokasi penyimpanan, serta aktivitas muat barang jadi ke truk untuk siap dipasarkan. 
Terkhusus untuk aktivitas-aktivitas pekerjaan muat barang jadi, seperti penarikan barang jadi ke lokasi truk menggunakan hand pallet, muat barang jadi ke dalam truk, penyusunan barang jadi didalam truk. Aktivitas-aktivitas tersebut dilakukan terus-menerus dan berulang-ulang selama bekerja, banyaknya grey yang perlu dimuat menunjukkan durasi kerja yang tinggi pula. Hal ini menyebabkan durasi operator terpapar bahaya ditempat kerja juga semakin tinggi. Selain itu, perlatan kerja dan postur kerja tidak ergonomis.

Postur kerja merupakan titik penentu dalam menganalisa keefektifan dari suatu pekerjaan. Apabila postur kerja yang dilakukan oleh operator sudah baik dan ergonomis maka dapat dipastikan hasil yang diperoleh oleh operator tersebut akan baik. Akan tetapi bila postur kerja operator yang kurang baik dan pekerjaan tersebut dilakukan secara terus menerus akan berdampak buruk pada pekerja ((Rahmadita Filaili, 2016)

\section{LANDASAN TEORI}

Pada penelitian sebelumnya analisis postur kerja dengan REBA untuk pekerja bangunan konstruksi ditemukan bahwa skor REBA lebih dari 6 artinya harus dilakukan perbaikan pada sisem kerja pembangunan (Hartanti and Sari, 2021). Sedangkan pada penelitian di perusahaan manufaktur pengolahan kopi dihasilkan kesimpulan skor REBA untuk operator roasting, mixing, grinding, dan packing 4 adalah lebih dari 6 yang mengindikasikan bahwa pekerjaan-pekerjaan tersebut tergolong dalam resiko sedang sehingga perlu dilakukan investigasi lanjutan (Tiogana and Hartono, 2020). Sekitar 53\% pekerja pada industri skala kecil di India berada pada tingkat risiko sedang tinggi sehingga membutuhkan tindakan yang diperlukan segera. Sekitar 33\% pekerja berada pada tingkat risiko sedang dan membutuhkan perubahan yang diperlukan (Ansari and Sheikh, 2014).

Terdapat perbedaan penelitian ini dengan penelitian sebelumnya, yaitu pada obyek penelitian. Penelitian ini dikhususkan pada analisis terhadap postur kerja operator muat barang di gudang kain grey.

\section{Rapid Entire Body Assessment (REBA)}

Rapid Entire Body Assessment (REBA) adalah suatu metode dalam bidang ergonomi yang berfungsi secara cepat untuk menilai postur leher, punggung, lengan, pergelangan tangan, dan kaki seorang pekerja. Fungsi REBA yaitu untuk mengetahui seberapa tinggi resiko yang terjadi dari postur kerja seorang operator dan dapat digunakan untuk perbaikan rancangan stasiun kerja. REBA adalah alat penganalisa postur tubuh yang bisa memeriksa aktivitas kerja. Penilaian postur kerja dengan metode REBA akan dilakukan dengan pemberian score/nilai pada setiap posturnya, semakin tinggi nilainya menandakan bahwa resiko yang terjadi saat bekerja semakin besar. Worksheet dari Rapid Entire Body Assessment (REBA) seperti tampak pada Gambar 1 berikut (McAtamney and Hignett, 2004).

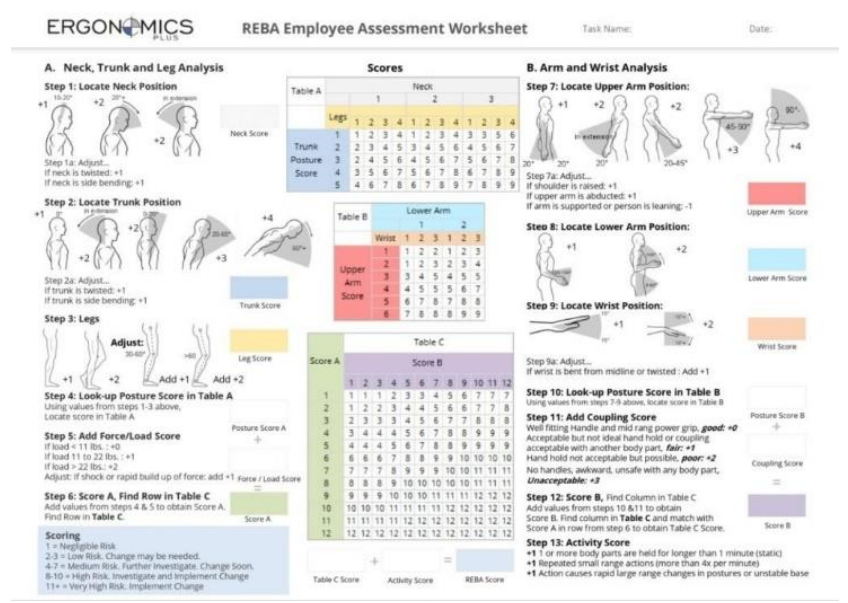

Gambar 1. Worksheet Rapid Entire Body Assessment (REBA)

\section{METODE PENELITIAN}


Penelitian ini dilakukan di bagian gudang pada proses muat barang jadi pada PT Surya Putra Mulia. Objek yang diamati adalah operator bagian gudang yang bertugas pada proses muat barang jadi. Satu orang operator yang bertugas melakukan penarikan barang jadi, dua operator yang bertugas muat barang jadi ke truk, dan satu operator yang bertugas menyusun barang jadi di truk. Data yang digunakan dalam penelitian ini adalah foto postur kerja operator. Selanjutnya dilakukan penilaian postur kerja untuk semua aktivitas pada proses muat barang jadi dengan menggunakan metode REBA. Waktu penelitian adalah bulan Januari 2021.

\section{HASIL DAN PEMBAHASAN}

Hasil penelitian berdasarkan jenis kelamin semua responden adalah berjenis kelamin laki - laki.

Rentang umur responden dibawah usia 45 tahun. Lama kerja responden yaitu 8 jam. Identitas operator disajikan pada Tabel 1 berikut.

Tabel 1. Identitas pekerja muat barang jadi

\begin{tabular}{|l|l|c|c|l|}
\hline No & Nama & Gender & Umur (Thn) & \multicolumn{1}{|c|}{ Job Description } \\
\hline 1 & L1 & Laki-laki & 43 & Penarikan Barang Jadi \\
\hline 2 & L2 & Laki-laki & 35 & Muat Barang Jadi ke Truk \\
\hline 3 & L3 & Laki-laki & 29 & Muat Barang Jadi ke Truk \\
\hline 4 & L4 & Laki-laki & 33 & Penyusunan Barang Jadi di Truk \\
\hline
\end{tabular}

\subsection{Penilaian Postur Kerja dengan Rapid Entire Body Assessment (REBA)}

Responden yang dinilai postur kerjanya adalah responden dengan tugas penarikan barang jadi, muat barang jadi ke truk, dan penyusunan barang jadi di truk.

\section{1. 1 Penarikan Barang Jadi}

Ilustrasi untuk operator yang melakukan kegiatan penarikan barang jadi dapat dilihat pada Gambar 2.

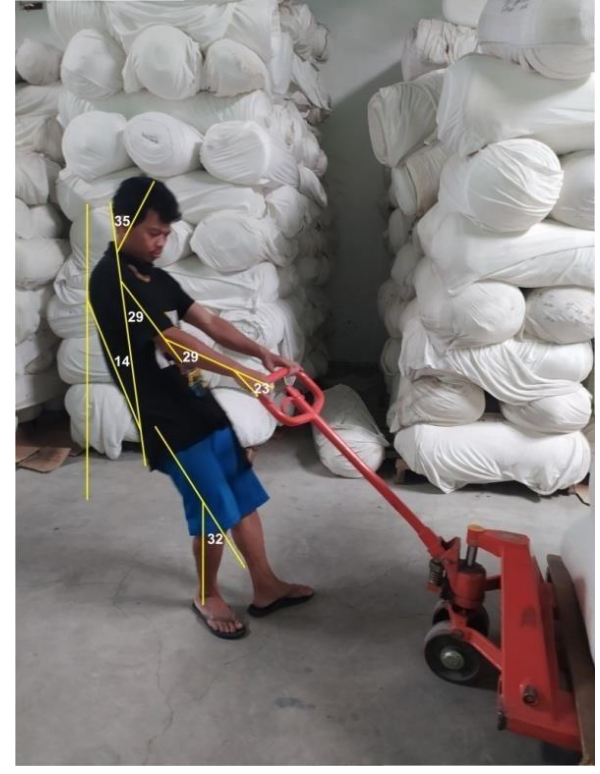

Gambar 2. Penarikan Barang Jadi

Tabel penilaian untuk skor REBA Tabel C seperti tampak pada Tabel 1 berikut. Tabel 1. Skor Table C 
Jurnal Inkofar * Volume 5 No. 2, Desember 2021 * ISSN: 2615-3645 (Print) / ISSN: 2581-2920 (Online)

Tersedia secara online di: http://www.politeknikmeta.ac.id/meta/ojs/

\begin{tabular}{|c|c|c|c|c|c|c|c|c|c|c|c|c|}
\hline \multirow{3}{*}{ Score A } & \multicolumn{110}{|c|}{ A able C } \\
\cline { 2 - 13 } & \multicolumn{10}{|c|}{ Ccore B } \\
\cline { 2 - 13 } & 1 & 2 & 3 & 4 & 5 & 6 & 7 & 8 & 9 & 10 & 11 & 12 \\
\hline 1 & 1 & 1 & 1 & 2 & 3 & 3 & 4 & 5 & 6 & 7 & 7 & 7 \\
\hline 2 & 1 & 2 & 2 & 3 & 4 & 4 & 5 & 6 & 6 & 7 & 7 & 8 \\
\hline 3 & 2 & 3 & 3 & 3 & 4 & 5 & 6 & 7 & 7 & 8 & 8 & 8 \\
\hline 4 & 3 & 4 & 4 & 4 & 5 & 6 & 7 & 8 & 8 & 9 & 9 & 9 \\
\hline 5 & 4 & 4 & 4 & 5 & 6 & 7 & 8 & 8 & 9 & 9 & 9 & 9 \\
\hline 6 & 6 & 6 & 6 & 7 & 8 & 8 & 9 & 9 & 10 & 10 & 10 & 10 \\
\hline 7 & 7 & 7 & 7 & 8 & 9 & 9 & 9 & 10 & 10 & 11 & 11 & 11 \\
\hline 8 & 8 & 8 & 8 & 9 & 10 & 10 & 10 & 10 & 10 & 11 & 11 & 11 \\
\hline 9 & 9 & 9 & 9 & 10 & 10 & 10 & 11 & 11 & 11 & 12 & 12 & 12 \\
\hline 10 & 10 & 10 & 10 & 11 & 11 & 11 & 11 & 12 & 12 & 12 & 12 & 12 \\
\hline 11 & 11 & 11 & 11 & 11 & 12 & 12 & 12 & 12 & 12 & 12 & 12 & 12 \\
\hline 12 & 12 & 12 & 12 & 12 & 12 & 12 & 12 & 12 & 12 & 12 & 12 & 12 \\
\hline
\end{tabular}

Skor Tabel C menunjukkan skor 6. Nilai Level Tindakan REBA tampak pada Tavel 2 di bawah ini.

Tabel 2. Nilai Level Tindakan REBA

\begin{tabular}{|c|c|l|}
\hline Skor REBA & Level resiko & \multicolumn{1}{|c|}{ Tindakan } \\
\hline 1 & Dapat diabaikan & Tidak diperlukan \\
\hline $2-3$ & Low & Mungkin diperlukan \\
\hline $4-7$ & Medium & Diperlukan \\
\hline $8-10$ & High & Segera diperlukan \\
\hline $11-15$ & Very high & Diperlukan sekarang \\
\hline
\end{tabular}

Skor REBA sebesar 6 termasuk dalam level resiko medium. Dengan demikian diperlukan Tindakan untuk dapat mengurangi terjadinya cedera otot.

\section{1. 2 Muat Barang Jadi ke Truk}

Kegiatan muat barang jadi ke truk dilakukan oleh dua orang operator. Ilustrasi operator 1 dalam kegiatan muat barang jadi ke truk seperti ditampilkan pada Gambar 3.

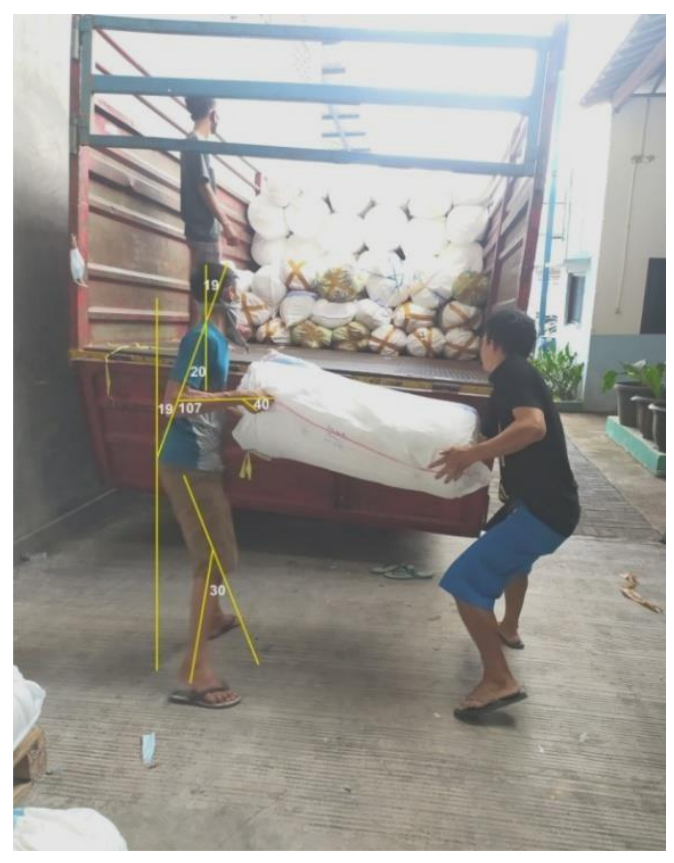

Gambar 3. Muat Barang Jadi ke Truk (a)

Tabel penilaian Skor Tabel C tertera pada Tabel 3 berikut. 
Tabel 3. Skor Table C

\begin{tabular}{|c|c|c|c|c|c|c|c|c|c|c|c|c|}
\hline \multirow{3}{*}{ Score A } & \multicolumn{10}{|c|}{ Aable C } \\
\cline { 2 - 15 } & \multicolumn{10}{|c|}{ B } \\
\cline { 2 - 15 } & 1 & 2 & 3 & 4 & 5 & 6 & 7 & 8 & 9 & 10 & 11 & 12 \\
\hline 1 & 1 & 1 & 1 & 2 & 3 & 3 & 4 & 5 & 6 & 7 & 7 & 7 \\
\hline 2 & 1 & 2 & 2 & 3 & 4 & 4 & 5 & 6 & 6 & 7 & 7 & 8 \\
\hline 3 & 2 & 3 & 3 & 3 & 4 & 5 & 6 & 7 & 7 & 8 & 8 & 8 \\
\hline 4 & 3 & 4 & 4 & 4 & 5 & 6 & 7 & 8 & 8 & 9 & 9 & 9 \\
\hline 5 & 4 & 4 & 4 & 5 & 6 & 7 & 8 & 8 & 9 & 9 & 9 & 9 \\
\hline 6 & 6 & 6 & 6 & 7 & 8 & 8 & 9 & 9 & 10 & 10 & 10 & 10 \\
\hline 7 & 7 & 7 & 7 & 8 & 9 & 9 & 9 & 10 & 10 & 11 & 11 & 11 \\
\hline 8 & 8 & 8 & 8 & 9 & 10 & 10 & 10 & 10 & 10 & 11 & 11 & 11 \\
\hline 9 & 9 & 9 & 9 & 10 & 10 & 10 & 11 & 11 & 11 & 12 & 12 & 12 \\
\hline 10 & 10 & 10 & 10 & 11 & 11 & 11 & 11 & 12 & 12 & 12 & 12 & 12 \\
\hline 11 & 11 & 11 & 11 & 11 & 12 & 12 & 12 & 12 & 12 & 12 & 12 & 12 \\
\hline 12 & 12 & 12 & 12 & 12 & 12 & 12 & 12 & 12 & 12 & 12 & 12 & 12 \\
\hline
\end{tabular}

Tabel C menunjukkan skor yang didapatkan adalah 4. Jenis Tindakan yang sesuai untuk skor 4 dapat ditunjukkan pada tabel 4 berikut.

Tabel 4. Nilai Level Tindakan REBA

\begin{tabular}{|c|c|l|}
\hline Skor REBA & Level resiko & \multicolumn{1}{|c|}{ Tindakan } \\
\hline 1 & Dapat diabaikan & Tidak diperlukan \\
\hline $2-3$ & Low & Mungkin diperlukan \\
\hline $4-7$ & Medium & Diperlukan \\
\hline $8-10$ & High & Segera diperlukan \\
\hline $11-15$ & Very high & Diperlukan sekarang \\
\hline
\end{tabular}

Level resiko untuk skor 4 adalah kategori resiko medium ( risk medium ). Dengan demikian tindakan untuk perbaikan postur diperlukan untuk mengurangi resiko MSDS. Operator 2 melakukan kegiatan muat barang jadi ke truk dengan dibantu oleh operator 1 seperti ditunjukkan oleh Gambar 4 berikut.

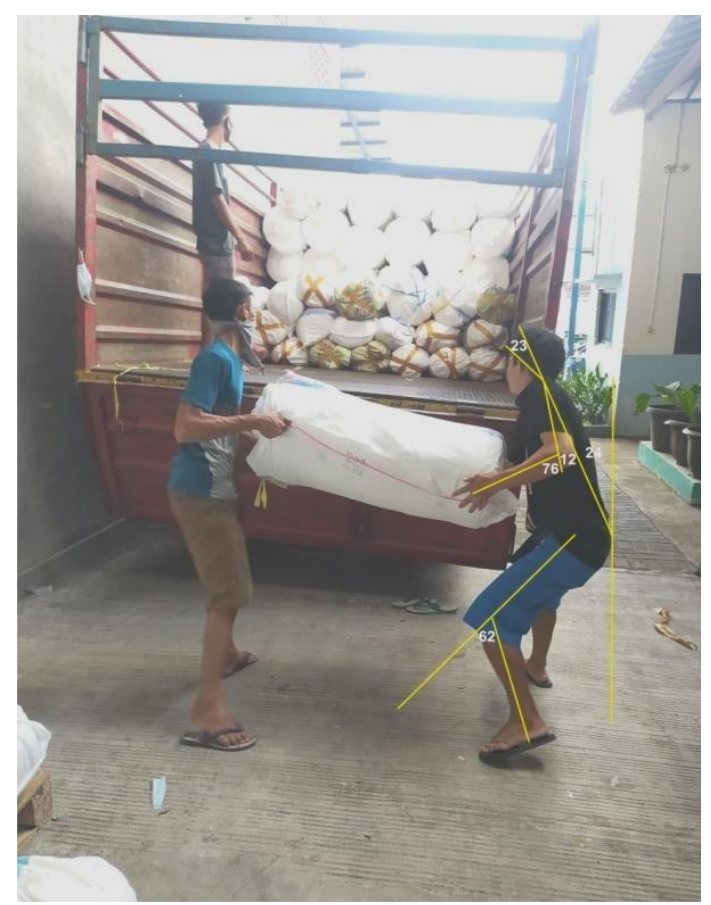

Gambar 4. Muat Barang Jadi ke Truk (b)

Hasil penilaian untuk Tabel $\mathrm{C}$ seperti ditunjukkan pada Tabel 5 berikut. 
Tabel 5. Tabel C untuk Operator 2 Muat Barang Jadi ke truk

\begin{tabular}{|c|c|c|c|c|c|c|c|c|c|c|c|c|}
\hline \multirow{3}{*}{ Score A } & \multicolumn{10}{|c|}{ Sable C } \\
\cline { 2 - 14 } & \multicolumn{10}{|c|}{ Score B } \\
\cline { 2 - 14 } & 1 & 2 & 3 & 4 & 5 & 6 & 7 & 8 & 9 & 10 & 11 & 12 \\
\hline 1 & 1 & 1 & 1 & 2 & 3 & 3 & 4 & 5 & 6 & 7 & 7 & 7 \\
\hline 2 & 1 & 2 & 2 & 3 & 4 & 4 & 5 & 6 & 6 & 7 & 7 & 8 \\
\hline 3 & 2 & 3 & 3 & 3 & 4 & 5 & 6 & 7 & 7 & 8 & 8 & 8 \\
\hline 4 & 3 & 4 & 4 & 4 & 5 & 6 & 7 & 8 & 8 & 9 & 9 & 9 \\
\hline 5 & 4 & 4 & 4 & 5 & 6 & 7 & 8 & 8 & 9 & 9 & 9 & 9 \\
\hline 6 & 6 & 6 & 6 & 7 & 8 & 8 & 9 & 9 & 10 & 10 & 10 & 10 \\
\hline 7 & 7 & 7 & 7 & 8 & 9 & 9 & 9 & 10 & 10 & 11 & 11 & 11 \\
\hline 8 & 8 & 8 & 8 & 9 & 10 & 10 & 10 & 10 & 10 & 11 & 11 & 11 \\
\hline 9 & 9 & 9 & 9 & 10 & 10 & 10 & 11 & 11 & 11 & 12 & 12 & 12 \\
\hline 10 & 10 & 10 & 10 & 11 & 11 & 11 & 11 & 12 & 12 & 12 & 12 & 12 \\
\hline 11 & 11 & 11 & 11 & 11 & 12 & 12 & 12 & 12 & 12 & 12 & 12 & 12 \\
\hline 12 & 12 & 12 & 12 & 12 & 12 & 12 & 12 & 12 & 12 & 12 & 12 & 12 \\
\hline
\end{tabular}

Tabel 5 menunjukkan bahwa skornya adalah 9. Penilaian tindakan dengan REBA tampak tertera pada Tabel 6 berikut.

Tabel 6. Nilai Level Tindakan REBA

\begin{tabular}{|c|c|l|}
\hline Skor REBA & Level resiko & \multicolumn{1}{|c|}{ Tindakan } \\
\hline 1 & Dapat diabaikan & Tidak diperlukan \\
\hline $2-3$ & Low & Mungkin diperlukan \\
\hline $4-7$ & Medium & Diperlukan \\
\hline $8-10$ & High & Segera diperlukan \\
\hline $11-15$ & Very high & Diperlukan sekarang \\
\hline
\end{tabular}

Skor 9 berada pada range skor REBA 8-10. Hal ini menunjukkan bahwa level resiko berada pada kategori high resiko, sehingga segera diperlukan tindakan perbaikan untuk mengurangi keluhan akibat MSDS.

\section{1. 3 Penyusunan Barang Jadi di Truk}

Operator yang sedang melakukan kegiatan penyusunan barang jadi ke truk tampak pada Gambar 5 berikut. Kegiatan ini hanya dilakukan oleh satu orang operator saja.

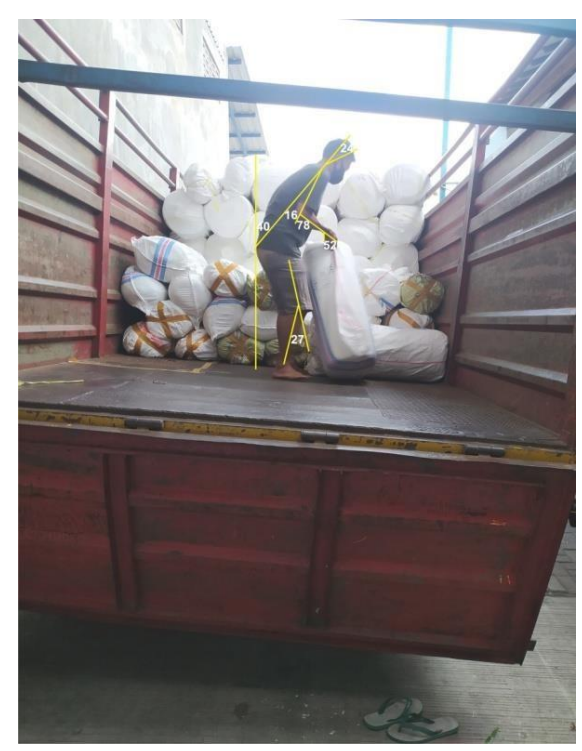

Gambar 5. Penyusunan Barang Jadi di Truk 
Tabel penilaian Skor Tabel C tertera pada Tabel 7 berikut.

Tabel 7. Skor Table C

\begin{tabular}{|c|c|c|c|c|c|c|c|c|c|c|c|c|}
\hline \multirow{3}{*}{ Score A } & \multicolumn{10}{|c|}{ Acoble C } \\
\cline { 2 - 15 } & \multicolumn{10}{|c|}{ B } \\
\cline { 2 - 14 } & 1 & 2 & 3 & 4 & 5 & 6 & 7 & 8 & 9 & 10 & 11 & 12 \\
\hline 1 & 1 & 1 & 1 & 2 & 3 & 3 & 4 & 5 & 6 & 7 & 7 & 7 \\
\hline 2 & 1 & 2 & 2 & 3 & 4 & 4 & 5 & 6 & 6 & 7 & 7 & 8 \\
\hline 3 & 2 & 3 & 3 & 3 & 4 & 5 & 6 & 7 & 7 & 8 & 8 & 8 \\
\hline 4 & 3 & 4 & 4 & 4 & 5 & 6 & 7 & 8 & 8 & 9 & 9 & 9 \\
\hline 5 & 4 & 4 & 4 & 5 & 6 & 7 & 8 & 8 & 9 & 9 & 9 & 9 \\
\hline 6 & 6 & 6 & 6 & 7 & 8 & 8 & 9 & 9 & 10 & 10 & 10 & 10 \\
\hline 7 & 7 & 7 & 7 & 8 & 9 & 9 & 9 & 10 & 10 & 11 & 11 & 11 \\
\hline 8 & 8 & 8 & 8 & 9 & 10 & 10 & 10 & 10 & 10 & 11 & 11 & 11 \\
\hline 9 & 9 & 9 & 9 & 10 & 10 & 10 & 11 & 11 & 11 & 12 & 12 & 12 \\
\hline 10 & 10 & 10 & 10 & 11 & 11 & 11 & 11 & 12 & 12 & 12 & 12 & 12 \\
\hline 11 & 11 & 11 & 11 & 11 & 12 & 12 & 12 & 12 & 12 & 12 & 12 & 12 \\
\hline 12 & 12 & 12 & 12 & 12 & 12 & 12 & 12 & 12 & 12 & 12 & 12 & 12 \\
\hline
\end{tabular}

Skor yang ditunjukkan oleh Tabel C menunjukkan angka 6. Nilai Level Tindakan REBA yang harus dilakukan seperti pada Tabel 8 berikut.

Tabel 8. Nilai Level Tindakan REBA

\begin{tabular}{|c|c|l|}
\hline Skor & Level resiko & \multicolumn{1}{|c|}{ Tindakan } \\
\hline 1 & Dapat diabaikan & Tidak diperlukan \\
\hline $2-3$ & Low & Mungkin \\
\hline $4-7$ & Medium & Diperlukan \\
\hline $8-$ & Hig & Segera diperlukan \\
\hline $11-15$ & Very high & Diperlukan \\
\hline
\end{tabular}

Berdasarkan Tabel 8 dapat diketahui bahwa tindakan diperlukan untuk mengurangi keluhan akibat MSDS. Rekapitulasi Penilaian Postur Kerja dengan Metode REBA seperti ditunjukkan oleh Tabel 9.

Tabel 9. Rekapitulasi Penilaian Postur Kerja dengan Metode REBA

\begin{tabular}{|l|c|c|c|}
\hline \multicolumn{1}{|c|}{ Kegiatan } & Gambar & Level Tindakan & Level Risiko dan \\
\hline Penarikan barang jadi & 2 & 6 & Sedang dan perlu \\
\hline Muat barang jadi ke truk & 3 & 4 & Sedang dan perlu \\
\cline { 2 - 5 } & 4 & 9 & Tinggi dan segera \\
\hline Penyusunan barang jadi di & 5 & 6 & Sedang dan perlu \\
\hline
\end{tabular}

Upaya yang dilakukan pada postur kerja adalah dengan menurunkan hasil skor dari metode REBA yang saat ini dengan nilai skor usulan. Usulan Postur Kerja dengan Metode REBA pada Gambar 2 atau operator penarikan barang jadi disajikan pada Tabel 10. Sedangkan Tabel 11 menyajikan Usulan Postur Kerja dengan Metode REBA pada operator 1 muat barang jadi ke truk. Usulan Postur Kerja dengan Metode REBAuntuk operator 2 muat barang jadi ke truk akan disajikan pada Tabel 12. Usulan Postur Kerja untuk operator penyusunan barang jadi di truk dapat dilihat pada Tabel 13. 
Tabel 10. Usulan Postur Kerja dengan Metode REBA pada Gambar 2

\begin{tabular}{lcccc}
\hline \multirow{2}{*}{ Faktor } & \multicolumn{2}{c}{ Kondisi saat ini } & \multicolumn{2}{c}{ Postur usulan } \\
\cline { 2 - 5 } & Pergerakan & Skor & Pergerakan & Skor \\
\hline Leher & $>20$ & 2 & $10-20$ & 1 \\
Punggung & $0-20$ & 2 & $0-20$ & 2 \\
Kaki & Kaki tertopang, 30-60 & 2 & Kaki tertopang, <30 & 1 \\
Beban & $>10 \mathrm{~kg}$ & 2 & $>10 \mathrm{~kg}$ & 2 \\
Lengan atas & $20-45$ & 2 & $0-20$ & 1 \\
Lengan bawah & $0-60$ & 2 & $0-60$ & 2 \\
Pergelangan & $>15$ & 2 & 15 & 1 \\
Genggaman & Baik & 0 & Baik & 0 \\
Aktivitas & & 0 & & 0 \\
\hline & Skor REBA & 6 & & 3 \\
\hline
\end{tabular}

Tabel 11. Usulan Postur Kerja dengan Metode REBA pada Gambar 3

\begin{tabular}{lcccc}
\hline \multirow{2}{*}{ Faktor } & \multicolumn{2}{c}{ Kondisi saat ini } & \multicolumn{2}{c}{ Postur usulan } \\
\cline { 2 - 5 } & Pergerakan & Skor & Pergerakan & Skor \\
\cline { 2 - 5 } Leher & $10-20$ & 1 & $10-20$ & 1 \\
Punggung & $0-20$ & 2 & 0 & 1 \\
Kaki & Kaki tertopang, 30-60 & 2 & Kaki tertopang, $<30$ & 1 \\
Beban & $>10 \mathrm{~kg}$ & 2 & $>10 \mathrm{~kg}$ & 2 \\
Lengan atas & $0-20$ & 1 & $0-20$ & 1 \\
Lengan bawah & $>100$ & 2 & $60-100$ & 1 \\
Pergelangan & $>15$ & 2 & 15 & 1 \\
Genggaman & Sedang & 1 & Baik & 0 \\
Aktivitas & & 0 & & 0 \\
\hline & Skor REBA & 4 & & 2 \\
\hline
\end{tabular}

Tabel 12. Usulan Postur Kerja dengan Metode REBA pada Gambar 4

\begin{tabular}{lcccc}
\hline & \multicolumn{2}{c}{ Kondisi saat ini } & \multicolumn{2}{c}{ Postur usulan } \\
\cline { 2 - 5 } \multicolumn{1}{c}{ Faktor } & Pergerakan & Skor & Pergerakan & Skor \\
\cline { 2 - 5 } Leher & $>20$ & 2 & $10-20$ & 1 \\
Punggung & $20-60$ & 3 & $0-20$ & 2 \\
Kaki & Kaki tidak tertopang, $>60$ & 4 & Kaki tertopang, $<30$ & 1 \\
Beban & $>10 \mathrm{~kg}$ & 2 & $>10 \mathrm{~kg}$ & 2 \\
Lengan atas & $0-20$ & 1 & $0-20$ & 1 \\
Lengan bawah & $60-100$ & 1 & $60-100$ & 1 \\
Pergelangan & 15 & 1 & 15 & 1 \\
Genggaman & Sedang & 1 & Baik & 0 \\
Aktivitas & & 0 & & 0 \\
\hline & Skor REBA & 9 & & 3 \\
\hline
\end{tabular}


Jurnal Inkofar * Volume 5 No. 2, Desember 2021 * ISSN: 2615-3645 (Print) / ISSN: 2581-2920 (Online)

Tersedia secara online di: http://www.politeknikmeta.ac.id/meta/ojs/

Tabel 13. Usulan Postur Kerja dengan Metode REBA pada Gambar 5

\begin{tabular}{|c|c|c|c|c|}
\hline \multirow{2}{*}{ Faktor } & \multicolumn{2}{|l|}{ Kondisi saat ini } & \multicolumn{2}{|c|}{ Postur usulan } \\
\hline & Pergerakan & Skor & Pergerakan & Skor \\
\hline Leher & $>20$ & 2 & $10-20$ & 1 \\
\hline Punggung & $20-60$ & 3 & $0-20$ & 2 \\
\hline Kaki & Kaki tertopang, $<30$ & 1 & Kaki tertopang, $<30$ & 1 \\
\hline Beban & $>10 \mathrm{~kg}$ & 2 & $>10 \mathrm{~kg}$ & 2 \\
\hline Lengan atas & $0-20$ & 1 & $0-20$ & 1 \\
\hline Lengan bawah & $60-100$ & 1 & $60-100$ & 1 \\
\hline Pergelangan & $>15$ & 2 & 15 & 1 \\
\hline Genggaman & Sedang & 1 & Baik & 0 \\
\hline Aktivitas & & 0 & & 0 \\
\hline & Skor REBA & 6 & & 3 \\
\hline
\end{tabular}

\section{KESIMPULAN}

Berdasarkan hasil penelitian yang dilakukan maka dapat ditarik kesimpulan sebagai berikut:

1. Hasil penilaian postur kerja dengan metode REBA untuk kegiatan penarikan barang jadi adalah level risiko sedang yang berarti diperlukan perbaikan pada postur ini. Untuk kegiatan operator 1 muat barang jadi ke truk adalah level risiko sedang yang berarti diperlukan perbaikan pada postur ini, sedangkan pada operator 2 muat barang jadi ke truk level risiko tinggi yang berarti diperlukan tindakan perbaikan segera. Untuk kegiatan penyusunan barang jadi di truk adalah level risiko sedang yang berarti diperlukan perbaikan pada postur ini.

2. Adapun usulan perbaikan yang dapat diberikan yaitu melakukan perbaikan postur kerja usulan dari hasil perhitungan yang dilakukan dengan metode REBA dari kondisi saat ini. Hasil usulan perbaikan postur kerja pada operator Penarikan Barang Jadi dari skor 6 menjadi skor 3, pada operator 1 Muat Barang Jadi ke Truk dari skor 4 menjadi skor 2, pada operator 2 Muat Barang Jadi ke Truk dari skor 9 menjadi skor 3, dan pada operator Penyusunan Barang Jadi di Truk dari skor 6 menjadi skor 3. Pada proses penarikan barang jadi diberikan usulan dengan mengurangi beban yang diangkut. Kemudian menambahkan alat bantu pada proses muat barang jadi ke truk berupa hand stacke.

\section{DAFTAR PUSTAKA}

Ansari, N. A. and Sheikh, D. M. J. (2014) 'Evaluation of work Posture by RULA and REBA: A Case Study', IOSR Journal of Mechanical and Civil Engineering, 11(4), pp. 18-23. doi: 10.9790/1684-11431823.

Hartanti, S. and Sari, M. P. (2021) 'Analisis Perbaikan Postur Kerja dengan Cornell Musculoskeletal Discomfort Questionnaires ( CMDQ ) dan Metode Rapid Entire Body Assesment ( REBA ) Beban Fisik Pekerja Konstruksi ( Studi Kasus: Pembangunan Jembatan Mlowo, Cs Nguter Sukoharjo )', Seminar Nasional Teknik dan Manajemen Industri dan Call for Paper ( SENTEKMI 2021 ), 1(November), pp. 160-166.

McAtamney, L. and Hignett, S. (2004) 'Rapid Entire Body Assessment', Handbook of Human Factors and Ergonomics Methods, 31, pp. 8-1-8-11. doi: 10.1201/9780203489925.ch8.

Rahmadita Filaili (2016) 'Analisis Beban Kerja Menggunakan Pendekatan Calory Expenditure Dan Evaluasi Postur Tubuh Dengan Rapid Entire Body Assessment (REBA)', Tugas Akhir Institut Teknologi Sepuluh November.

Tiogana, V. and Hartono, N. (2020) 'Analisis Postur Kerja dengan Menggunakan REBA dan RULA di PT X’, Journal of Integrated System, 3(1), pp. 9-25. doi: 10.28932/jis.v3i1.2463. 